\title{
Hidroksiapatit kristalizasyonunun pentanoik asit varlığında incelenmesi
}

\author{
Perviz SAYAN*, Sevgi POLAT, Ayça KARA \\ Marmara Üniversitesi, Mühendislik Fakültesi, Kimya Mühendisliği Bölümü, Göztepe Kampüsü, Ístanbul \\ Geliș Tarihi (Received Date): 13.10 .2019 \\ Kabul Tarihi (Accepted Date): 13.03.2020
}

$\ddot{\mathbf{O} z}$

Bu çalışmada önemli bir yă̆ asidi olan pentanoik asidin hidroksiapatit kristalizasyonu üzerine olan etkisi incelenmiştir. Bu amaçla kristalizasyon deneyleri saf ortamda ve 100, 500 ve 1000 ppm olmak üzere üç farkl pentanoik asit konsantrasyonunda kesikli bir sistemde yürütülmüştür. Elde edilen hidroksiapatit kristalleri, XRD, SEM, tane boyutu, BET, FTIR, zeta potansiyeli ve TG analiz yöntemleri kullanılarak karakterize edilmiştir. Pentanoik asit varliğında, hidroksiapatit kristallerin ortalama tane boyutunun saf ortama göre arttı̆̆l, kristal morfolojisinde önemli değişiklikler meydana geldiği belirlenmiştir. FTIR analiz sonuçları, katkı maddesi olarak kullanılan pentanoik asidin kristal yüzeyine tutunduğunu göstermiş ve bu sonuçlar zeta potansiyeli ölçümleri ile desteklenmiştir. Saf ortamda üretilen hidroksiapatit kristallerinin zeta potansiyeli $-20,9 \pm 1,1 \mathrm{mV}$ iken kristallerin yüzey yükleri 1000 ppm pentanoik asit konsantrasyonunda $+2,1 \pm 1,3 \mathrm{mV}$ değerine ulaşmıştır. Ayrıca hidroksiapatit kristallerinin termal bozunma kinetiği Kissinger ve Coats-Redfern yöntemleri kullanilarak incelenmiştir. Saf ortamda elde edilen hidroksiapatit kristallerinin termal bozunmasi sirasinda gerekli olan ortalama aktivasyon enerjisi Kissinger modeli kullanilarak $538,51 \mathrm{~kJ} / \mathrm{mol}$ olarak belirlenmiştir. Bu değer pentanoik asit ortamında üretilen kristaller için ise 580,99 kJ/mol olarak hesaplanmıştır. Coats Redfern kinetik modeline göre hem saf hem de katkı ortamı için 3D difüzyon modelinin hidroksiapatitin termal bozunma sürecini en iyi karakterize eden mekanizma olduğu belirlenmiştir.

Anahtar kelimeler: Hidroksiapatit, kristalizasyon, pentanoik asit, karakterizasyon.

\footnotetext{
* Perviz SAYAN, perviz.sayan@ marmara.edu.tr, https://orcid.org/0000-0003-4407-6464

Sevgi POLAT, sevgi.polat@marmara.edu.tr, https://orcid.org/0000-0002-0934-2125

Ayça KARA, aycakara@windowslive.com, https://orcid.org/0000-0003-0157-0171
} 


\title{
Hydroxyapatite crystallization in the presence of pentanoic acid
}

\begin{abstract}
The effect of pentanoic acid, an important fatty acid, on hydroxyapatite crystallization was investigated in this study. The crystallization experiments were performed in pure media and in the presence of three different pentanoic acid concentrations as 100, 500 and $1000 \mathrm{ppm}$ in a batch system. The hydroxyapatite crystals obtained were characterized by XRD, SEM, particle size, BET, FTIR, zeta potential and TG analysis techniques. Compared to pure media, the particle size of the hydroxyapatite obtained in pentanoic acid media increased, significant changes in crystal morphology were determined. The results of FTIR showed that pentanoic acid used as the additive adsorbed onto the surface of the hydroxyapatite crystals and this result was supported by zeta potential measurements. While the zeta potential of hydroxyapatite crystals obtained in pure media was $-20.9 \pm 1.1 \mathrm{mV}$, this value was $+2.1 \pm 1.3 \mathrm{mV}$ for 1000 ppm pentanoic acid media. In addition, the thermal decomposition kinetics of hydroxyapatite crystal was investigated using Kissinger and Coats-Redfern models. The average activation energy value for the decomposition of crystals was $538.51 \mathrm{~kJ} / \mathrm{mol}$. This value was calculated as $580.99 \mathrm{~kJ} / \mathrm{mol}$ for crystals obtained in pentanoic acid media. According to the Coats Redfern kinetic model, the 3D diffusion model was determined to be the best model to characterize the thermal decomposition behavior of the hydroxyapatite crystals.
\end{abstract}

Keywords: Hydroxyapatite, crystallization, pentanoic acid, characterization.

\section{Giriş}

Hidroksiapatit $\left(\mathrm{Ca}_{10}\left(\mathrm{PO}_{4}\right)_{6}(\mathrm{OH})_{2}\right.$, HAP) termodinamik açıdan en kararlı kalsiyum fosfat tuzlarından biridir [1]. Hidroksiapatit kristalleri toksik ve alerjenik olmayan, stabil, biyoaktif ve biyouyumlu yapıya sahip olmaları nedeniyle biyomalzemelerin hazırlanmasında yaygın olarak kullanılmaktadır [2]. Aynı zamanda, sentetik hidroksiapatitin kimyasal bileşimi ve özellikleri, diş ve kemiklerin inorganik mineral bileşenlerine büyük benzerlik göstermektedir [3,4]. Bu nedenle, bu kristaller başta diş hekimliği ve ortopedi klinik uygulamaları olmak üzere pek çok farklı biyomedikal uygulamalarda kullanılmaktadır [5,6].

Yapılan çalışmalar kristalizasyon işlemi sonucunda elde edilen hidroksiapatit kristallerinin özelliklerinin $\mathrm{pH}$, sıcaklık, aşırı doygunluk gibi operasyon koşullarına bağlı olarak farklılıklar gösterebileceğini ortaya koymuştur [7-9]. Aynı zamanda kristalizasyon ortamına ilave edilen katkı maddeleri ile de oluşan hidroksiapatitin yüzey alanı, morfolojisi, tane boyutu ve yüzey yükleri gibi fiziksel özellikleri değiştirilebilmektedir [10-12]. Katkı maddelerinin genel olarak kristalizasyon üzerine etkileri çok farklı mekanizmalarla olabilmektedir. Ancak hepsinde de kimyasal veya fiziksel kuvvetlerle bu katkıların kristal yüzeyine adsorplanması temel aşamadır [13]. Yapılan bu çalışmada, hidroksiapatit kristalizasyonu saf ortamda ve biyouyumluluk özelliği gösteren ve katkı maddesi olarak kullanılan pentanoik asit varlığında gerçekleştirilmiştir. Elde edilen kristallerin yapısı, morfolojisi, yüzey alanları, fonksiyonel grupları ve yüzey yükleri belirlenmiştir. Ayrıca, hidroksiapatitin termal 
bozunma davranışı termogravimetrik analiz cihazı kullanılarak incelenmiştir. Termal bozunma verileri kullanılarak saf ve katkı ortamında üretilen kristallerin ortalama aktivasyon enerjileri hesaplanmıştır.

\section{Deneysel çalışmalar}

\subsection{Deneyin yapılışı}

Deneylerde analitik saflıkta ve Merck firmasından temin edilen kalsiyum klorür $\left(\mathrm{CaCl}_{2}\right)$, potasyum dihidrojen fosfat $\left(\mathrm{KH}_{2} \mathrm{PO}_{4}\right)$, potasyum hidroksit $(\mathrm{KOH})$ ve pentanoik asit $\left(\mathrm{C}_{5} \mathrm{H}_{10} \mathrm{O}_{2}\right)$ kullanılmıştır.

Deneyler 1L aktif hacme sahip çift ceketli cam kristalizörde, $70^{\circ} \mathrm{C}$ sicaklıkta, $\mathrm{pH}=9,5^{\prime}$ 'te ve 600 rpm karıştırma hızında yürütülmüştür. Deney düzeneği Şekil 1'de verilmiştir.

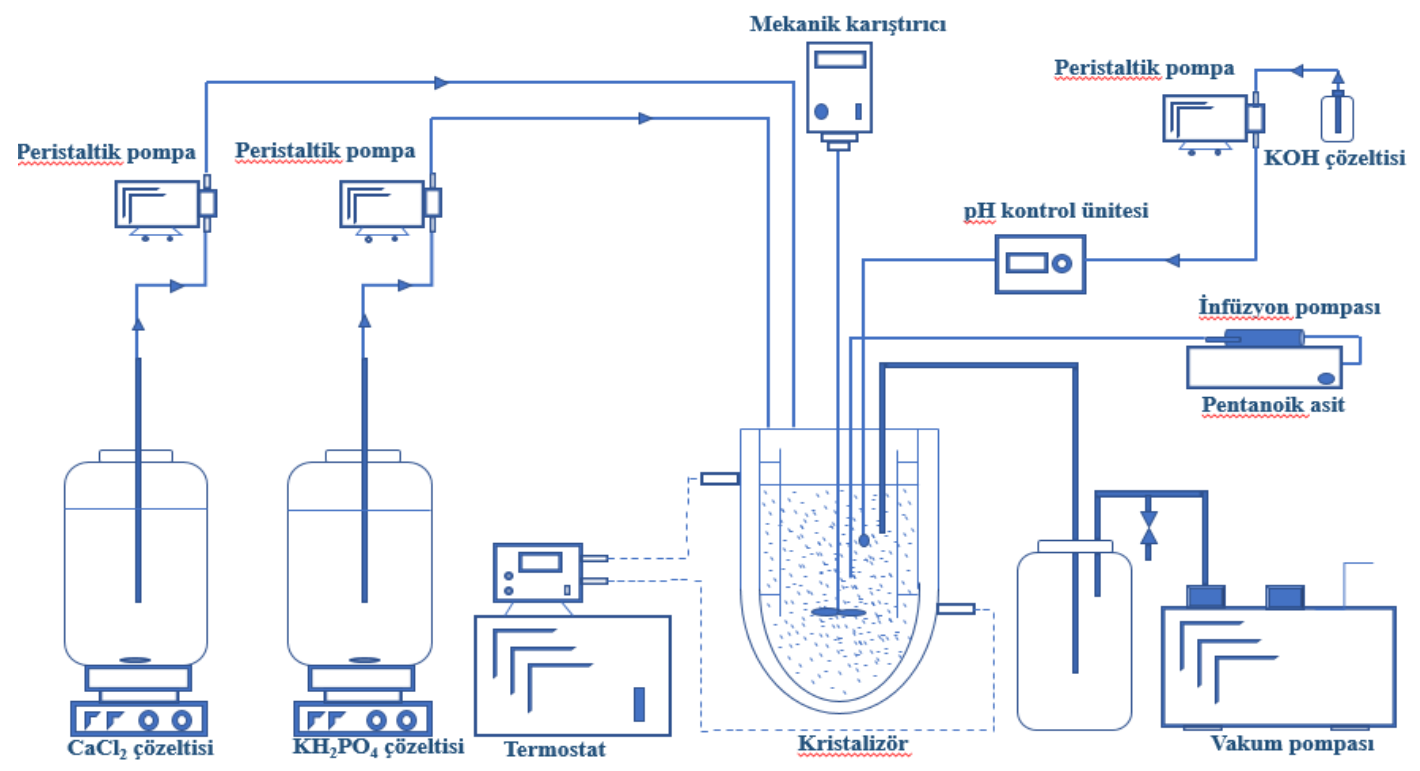

Şekil 1. Deney düzeneği.

İlk olarak $0,1 \mathrm{M}^{\prime} l 1 \mathrm{k} \mathrm{KOH}, 0,5 \mathrm{M} \mathrm{CaCl} \mathrm{Cl}_{2}$ ve $0,3 \mathrm{M}^{\prime} l_{1} \mathrm{k} \mathrm{KH}_{2} \mathrm{PO}_{4}$ çözeltileri hazırlanmıştır. Deneylerin başlangıcında kristalizör içerisine $500 \mathrm{ml}$ hacminde saf su konmuş ve 70 ${ }^{\circ} \mathrm{C}$ 'de termal dengeye gelmesi için beklenmiştir. Termal dengeye erişildikten sonra 250 $\mathrm{ml} 0,5 \mathrm{M} \mathrm{CaCl}_{2}$ ve $250 \mathrm{ml} 0,3 \mathrm{M} \mathrm{KH}_{2} \mathrm{PO}_{4}$ çözeltileri peristaltik pompalar aracılığıyla 8 $\mathrm{ml} /$ dak hızla kristalizöre beslenmiş ve hidroksiapatit kristalizasyonu gerçekleştirilmiştir. Kristalizör içi sıcaklığı termostat, $\mathrm{pH}$ ise $\mathrm{pH}$ kontrol ünitesi ile senkronize olarak çalışan infüzyon pompası aracılığıyla 9,5 değerinde sabit tutulmuştur. $\mathrm{pH}$ ayarlanmasında 0,1M'lık KOH çözeltisi kullanılmıştır. Karıştırma işlemi üç kanatlı bir karıştırıcı eleman yardımı ile yapılıştır. Deney süresince kristalizörün kapağı kapatılmış ve çözeltinin üzerinden azot geçişi sağlanarak farklı kalsiyum fosfat bileşiklerinin oluşmaması sağlanmıştır. Deneylerde katkı maddesi olarak pentanoik asit kullanılmış ve deneyler 100, 500 ve 1000 ppm katkı maddesi konsantrasyonunda gerçekleştirilmiştir. Katk1 maddesi kristalizöre infüzyon pompası aracılığıyla sabit debide ve deney boyunca sürekli olacak şekilde beslenmiştir. 
Deney sonunda ele geçen hidroksiapatit kristalleri filtrelenerek ana çözeltisinden ayrılmış ve klorür iyonları kalmayıncaya kadar saf su ile yıkanmıştır. Klorür iyonunun kalıp kalmadığı gümüş nitrat çözeltisiyle belirlenmiştir. Klorür iyonlarından arındırılan kristaller saf su eklenen erlenmeyer flask içerisine alınmış ve çalkalamalı su banyosunda $37^{\circ} \mathrm{C}$ 'de $\mathrm{pH}=7,4$ 'te iki ay bekletilmiştir. Bu sürenin sonunda elde edilen kristaller filtrelenerek ayrılmış ve kurutulmuştur. Kurutulan nihai numunenin X-Işını Difraksiyon (XRD), taramalı elektron mikroskobu (SEM), Brunauer, Emmet ve Teller (BET), Fourier Dönüşümlü Kızı̈ötesi Spektroskopisi (FTIR), zeta potansiyeli ve termogravimetrik (TG) analizleri yapılmıştır.

\subsection{Kinetik analiz}

Katı hal reaksiyon kinetiği genel olarak eşitlik (1)'de verildiği gibi ifade edilmektedir.

$\frac{d x}{d t}=k(T) f(x)$

$k(T)$ fonksiyonu, Arrhenius hız eşitliğine göre sıcaklığa bağlı hız sabiti olarak aşağıdaki gibi tanımlanmaktadır.

$$
k(T)=A e^{(-E / R T)}
$$

$E(\mathrm{~kJ} / \mathrm{mol})$ aktivasyon enerjisi, $T$ sicaklık $(\mathrm{K}), R$ gaz sabiti $(8,314 \mathrm{~J} / \mathrm{mol} . \mathrm{K})$ ve $A(1 /$ dak $)$ frekans faktörüdür. Dönüşüm olarak tanımlanan $x$ ise aşağıdaki gibi tanımlanabilir.

$$
x=\frac{W_{0}-W_{t}}{W_{0}-W_{f}}
$$

Burada,

$\mathrm{W}_{0}$ : örneğin başlangıçtaki kütlesi, mg

$\mathrm{W}_{\mathrm{t}}$ : örneğin $\mathrm{t}$ anındaki kütlesi, $\mathrm{mg}$

$\mathrm{W}_{\mathrm{f}}$ örneğin bozunma sonrasındaki kütlesi, mg

Arrhenius eşitliğinde bulunan hız sabitinin eşitlik (1)'de yerine konulmasıyla aşağıdaki ifade elde edilir.

$$
\frac{d x}{d t}=A f(x) e^{-E / R T}
$$

Sıcaklık sabit ısıtma hızı olan $\beta$ ile birlikte, zamanın fonksiyonudur ve aşağıdaki ifadeyle tanımlanmaktadır.

$$
\beta=\frac{d T}{d t}=\frac{d T}{d x} \frac{d x}{d t}
$$

Belirtilen eşitliklerin birleştirilmesi ve integralinin yazılmasıyla

$$
\int_{0}^{x} \frac{d x}{f(x)}=g(x)=\frac{A}{B} \int_{T_{0}}^{T} \exp \left(-\frac{E}{R T}\right) d T=\frac{A E}{\beta R} p(u)
$$


eşitliği elde edilir ve gerçek çözümü matematiksel metotlar ve yaklaşımlar ile çözülebilir.

Kissinger yöntemi [14], farklı 1sıtma hızlarında yapılan deneysel çalışmalara dayanır. $\mathrm{Bu}$ yöntemde maksimum bozunma sıcaklığı başka bir deyişle ekzotermik pik sıcaklığ $\left(\mathrm{T}_{\mathrm{m}}\right)$, her bir ısıtma hızında elde edilen sabit dönüşüm noktası olarak alınarak aktivasyon enerjisi aşağıdaki eşitlikle belirlenebilir:

$$
\ln \left(\frac{\beta}{T_{m}^{2}}\right)=\ln \left(\frac{A R}{E}\right)+\ln \left[n\left(1-x_{m}\right)^{n-1}\right]-\frac{E}{R T_{m}}
$$

Burada, $x_{m}$ maksimum bozunma sıcaklığındaki dönüşümü ifade eder. 1/T $\mathrm{m}$ 'e karşılık $\ln \left(\beta / T_{m}^{2}\right)$ değerlerinin grafiğe geçirilmesiyle elde edilen doğrusal grafiklerin eğimi $\mathrm{E} / \mathrm{R}$ değerini verir.

\section{Sonuçlar ve tartışma}

\subsection{XRD analizi}

Saf ve farklı pentanoik asit konsantrasyonlarında üretilen hidroksiapatit kristallerinin yapısını belirlemek için XRD analizi yapılmış ve sonuçlar Şekil 2'de verilmiştir.

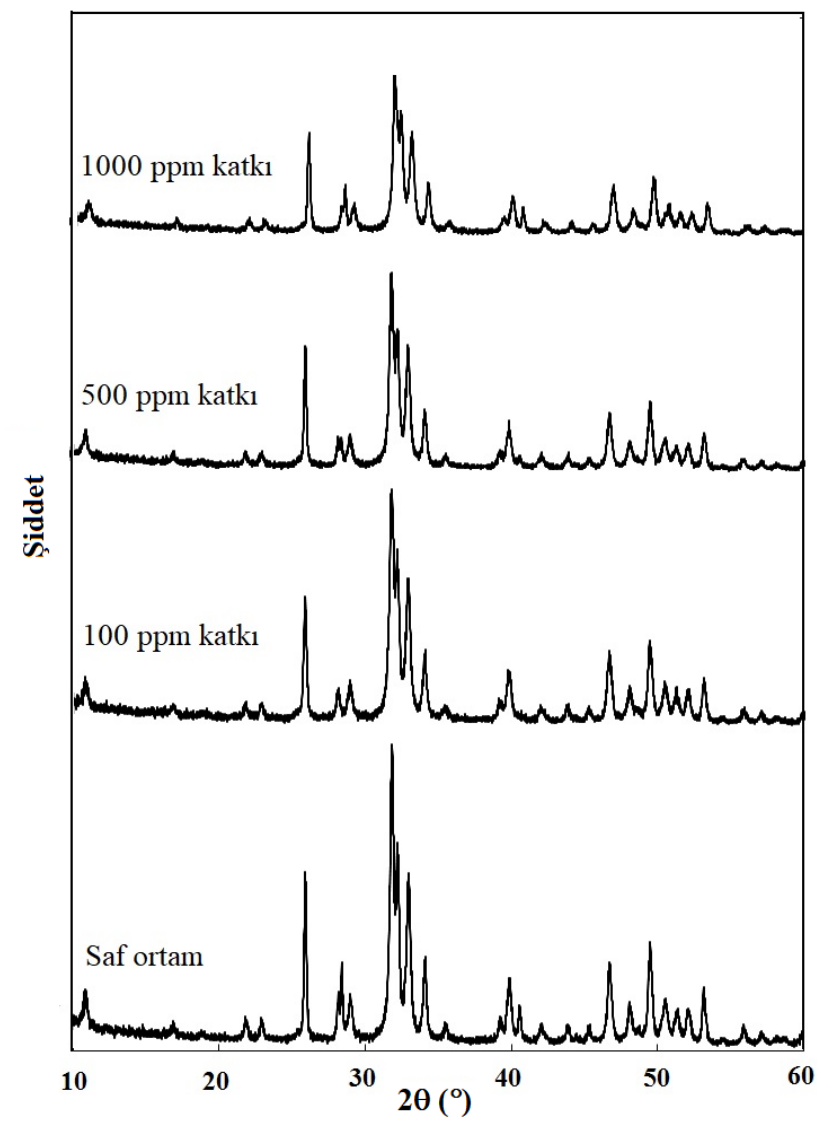

Şekil 2. Saf ve farklı katkı konsantrasyonlarında elde edilen hidroksiapatit kristallerinin XRD sonuçları. 
Saf ortamda üretilen kristaller için $2 \theta=26^{\circ}, 29^{\circ}, 32^{\circ}, 34^{\circ}, 40^{\circ}, 47^{\circ}$ ve $54^{\circ}$, de belirlenen pikler, hidroksiapatit yapısını karakterize etmektedir. Elde edilen sonuçlar literatürde verilen sonuçlarla da uyumluluk göstermektedir [15]. Saf ortam ile karşılaştırıldığında, pentanoik asit varlığında elde edilen hidroksiapatit kristallerinin XRD piklerinin şiddetlerinin azaldığ 1 görülmüştür. Pik şiddetinde görülen bu değişim pentanoik asidin kristal yapı ile bir etkileşim içerisinde olduğunu göstermektedir. Bu etkileşimin varlığ 1 , hidroksiapatit morfolojisini, fonksiyonel grubunu, yüzey yükünü ve BET yüzey alanı gibi fizikokimyasal özelliklerini etkileyebileceğine işaret etmektedir.

\subsection{SEM ve BET analizi}

Saf ortamda üretilen hidroksiapatit kristallerinin morfolojik yapısını belirleyebilmek ve pentanoik asidin kristal morfoloji üzerine olan olası etkisini gösterebilmek için SEM analizi yapılmış ve sonuçlar Şekil 3 'te verilmiştir.
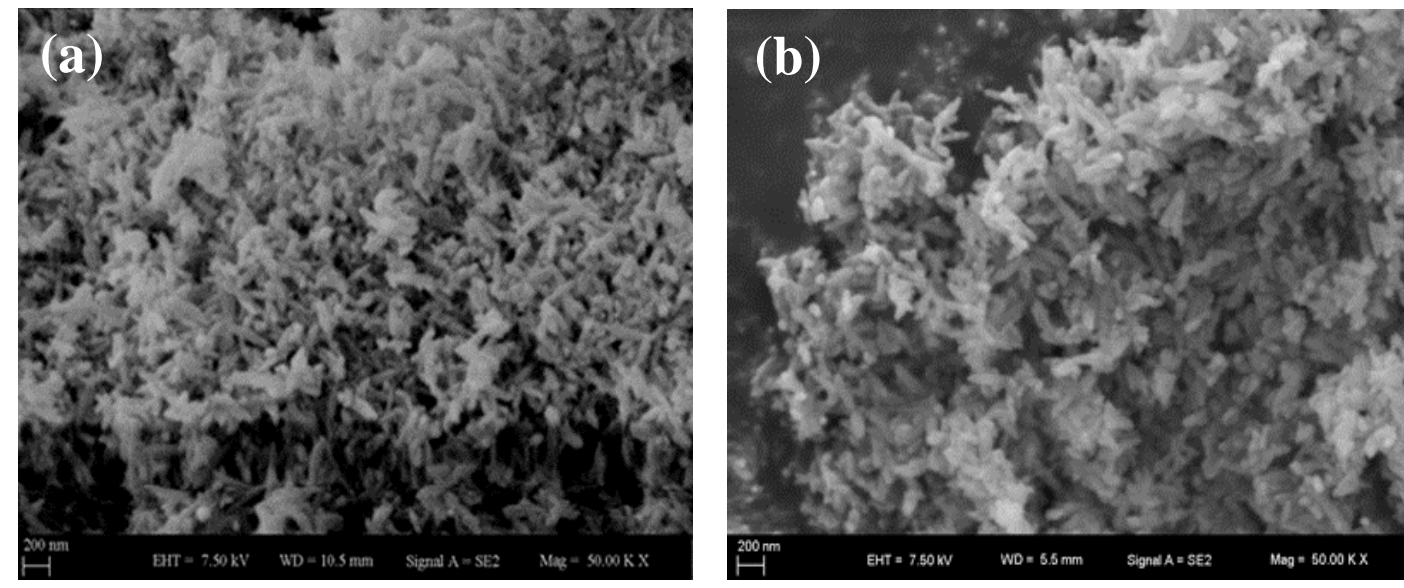

Şekil 3. a) Saf ortamda b) 1000 ppm pentanoik asit varlığında üretilen hidroksiapatit kristallerinin SEM fotoğrafi.

Şekil 3'ten de açıkça görüleceği üzere saf ortamda üretilen hidroksiapatit kristalleri nano boyutta olup birbirleri üzerinde büyümüş çubuk formundaki kristallerden meydana gelmişlerdir. Saf ortamda üretilen hidroksiapatit kristallerinin ortalama tane boyutları $283 \mathrm{~nm}$ olarak ölçülmüştür. Ayrıca kristaller şiddetli aglomerasyon eğilimi göstermektedirler. $\mathrm{Bu}$ sonuçlar literatürde verilen çalışmalarla da benzerlik göstermektedirler [16]. Katkı maddesi varlığında elde edilen kristallerin SEM fotoğrafları incelendiğinde, pentanoik asit varlığında kristallerin en boy oranlarının değiştiği, ortalama tane boyutlarının ve aglomerasyon şiddetinin arttığı belirlenmiştir. 1000 ppm pentanoik asit varlığgnda üretilen kristallerin ortalama tane boyutu $328 \mathrm{~nm}$ olarak ölçülmüştür.

$\mathrm{Bu}$ çalışmada ayrıca pentanoik asidin hidroksiapatit kristallerinin yüzey alanlarına olan etkisi belirlemek amacıyla BET analizleri yapılmış ve sonuçlar Şekil 4'te verilmiştir. Saf hidroksiapatit kristallerinin BET yüzey alanı $34,6 \mathrm{~m}^{2} / \mathrm{g}$ olarak belirlenmiştir. Pentanoik asit varlığında ise bu değer $25,9 \mathrm{~m}^{2} /$ g'a kadar düşmüştür. 


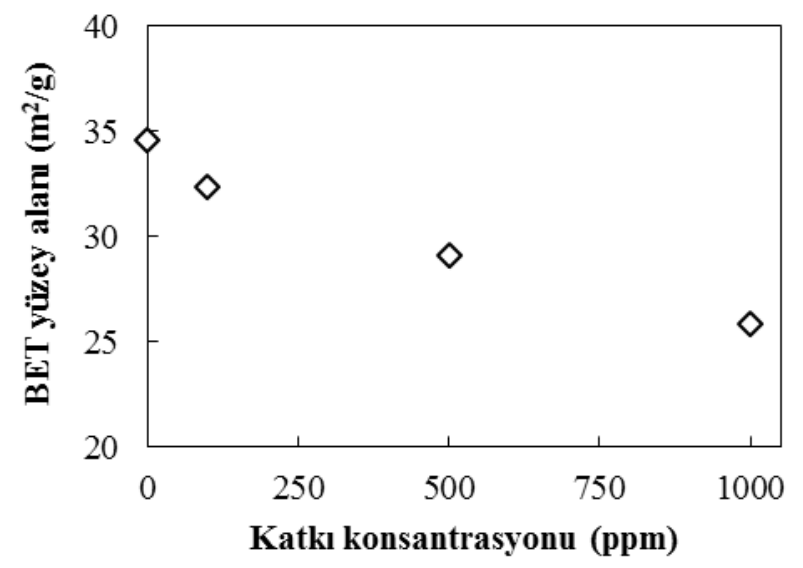

Şekil 4. Hidroksiapatit kristallerinin pentanoik asit konsantrasyonuna bağl1 BET yüzey alanı değişimi.

\subsection{FTIR analizi}

Hidroksiapatit kristallerinin fonksiyonel gruplarını belirlemek ve aynı zamanda pentanoik asitin kristal yüzeyine olan adsorpsiyon özelliklerini tespit edebilmek için FTIR analizi yapılmıştır. Saf ortamda ve 1000 ppm pentanoik asit varlığında elde edilen kristallerin FTIR spektrumları Şekil 5'te verilmiştir.

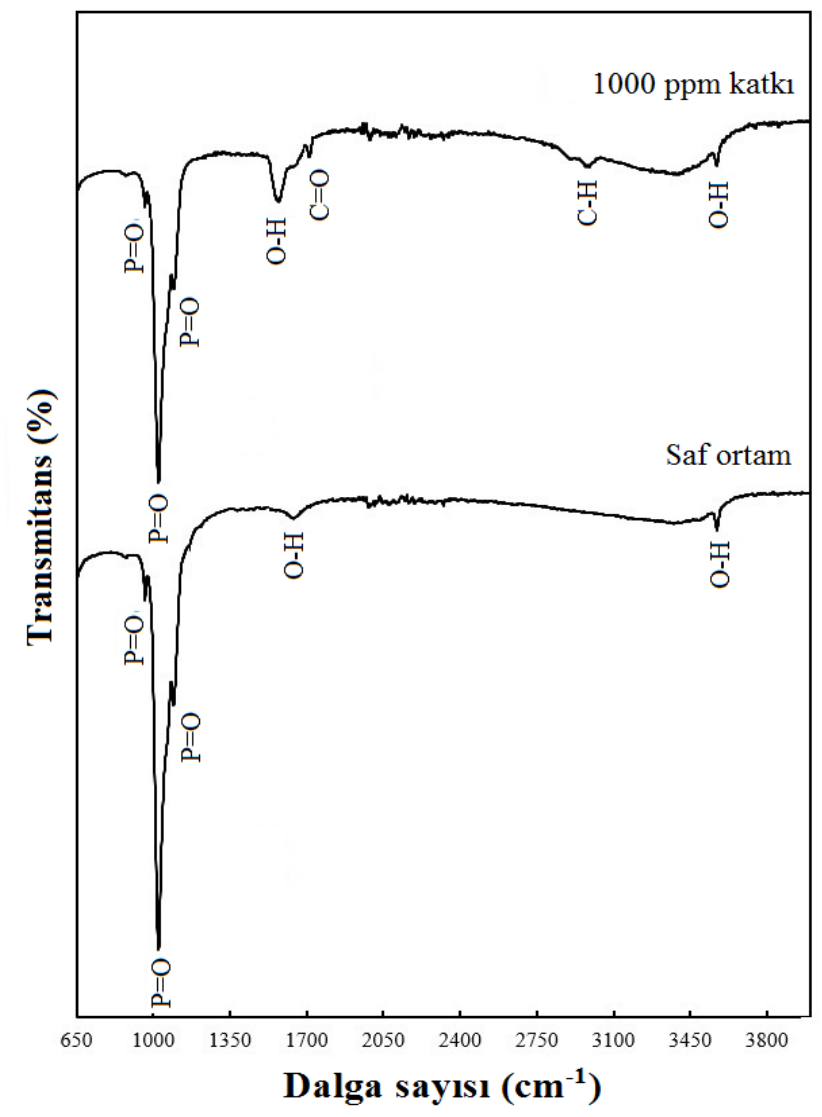

Şekil 5. Saf ortamda ve pentanoik asit varlığında üretilen hidroksiapatit kristallerinin FTIR spektrumları.

Saf ortamda üretilen hidroksiapatit kristalleri $960 \mathrm{~cm}^{-1}, 1021 \mathrm{~cm}^{-1}, 1091 \mathrm{~cm}^{-1}$ ve 3570 $\mathrm{cm}^{-1}$ dalga boyunda karakteristik absorpsiyon pikleri vermiştir. $3570 \mathrm{~cm}^{-1}$ dalga 
boyunda görülen pik -OH gerilme titreşimini gösterirken, 1091, 1024, $963 \mathrm{~cm}^{-1}$ de görülen pikler ise fosfat grubuna ait gerilme titreşimlerini göstermektedir. Elde edilen bu sonuçlar literatürdeki çalışmalar ile uyum içerisindedir [17]. Pentanoik asit varlığında elde edilen hidroksiapatit kristallerin FTIR analizinde ise bu piklere ek olarak yaklaşık olarak $1700 \mathrm{~cm}^{-1}$ ve $2900 \mathrm{~cm}^{-1}$ dalga boylarında yeni pikler tespit edilmiştir. $\mathrm{Bu}$ pikler pentanoik asiti karakterize etmekte olup, katkı maddesinin kristal yüzeyine adsorplandığını göstermektedir.

\subsection{Zeta potansiyeli analizi}

Pentanoik asidin hidroksiapatit kristal yüzeyine adsorpsiyonuna bağlı olarak yüzey potansiyellerinde görülebilecek olası değişimleri belirlemek için zeta potansiyel ölçümleri yapılmıştır. Pentanoik asit konsantrasyonuna bağlı olarak değişen zeta potansiyeli ölçüm değerleri Şekil 6' da verilmiştir.

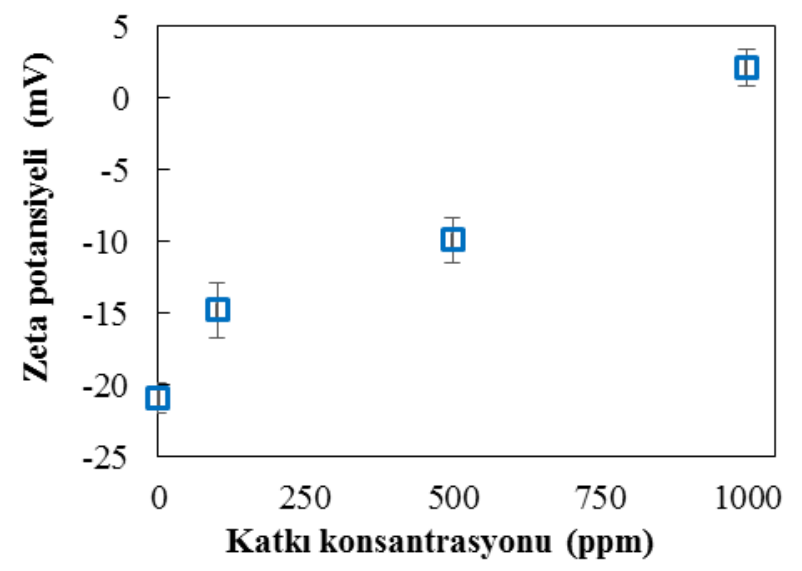

Şekil 6. Saf ve farklı katkı konsantrasyonlarında üretilen kristallerin zeta potansiyeli değerleri.

Saf hidroksiapatit kristalleri için zeta potansiyel değeri $\mathrm{pH}=7,4$ 'te $-20,9 \pm 1,1 \mathrm{mV}$ olarak ölçülmüş̧ür. Pentanoik asit varlığında ise hidroksiapatit kristallerinin zeta potansiyeli değeri katk1 konsantrasyonun 100 ppm'den 1000 ppm'e çıkarılmasıyla -14,8 $\pm 1,9$ $\mathrm{mV}$ 'dan $+2,1 \pm 1,3 \mathrm{mV}$ değerine yükselmiştir. Pentanoik asidin yüksek konsantrasyonlarında zeta potansiyel değerinin izoelektrik noktaya yaklaşması agglomerasyon eğiliminin artacağının bir göstergesidir. Nitekim SEM fotoğraflarının da yüksek katkı maddesi konsantrasyonlarında agglomerasyon eğilimini ortaya koyduğu sonucunu desteklemektedir. Aynı zamanda zeta potansiyelinde görülen bu belirgin değişim pentanoik asidin kristal yüzeyine tutunduğunu kanıtlamakta ve FTIR sonuçlarını desteklemektedir.

\subsection{TG/DTA analizi}

Saf ve katkı maddesi varlığında üretilen hidroksiapatit kristallerinin termal bozunma davranışı $10{ }^{\circ} \mathrm{C} /$ dak 1 sıtma hızında, 30-1200 ${ }^{\circ} \mathrm{C}$ bozunma sıcaklık aralığında incelenmiştir. Saf ortamda ve 1000 ppm pentanoik asit varlığında üretilen kristallerin TGA/DTA eğrileri Şekil 7'de verilmiştir. 

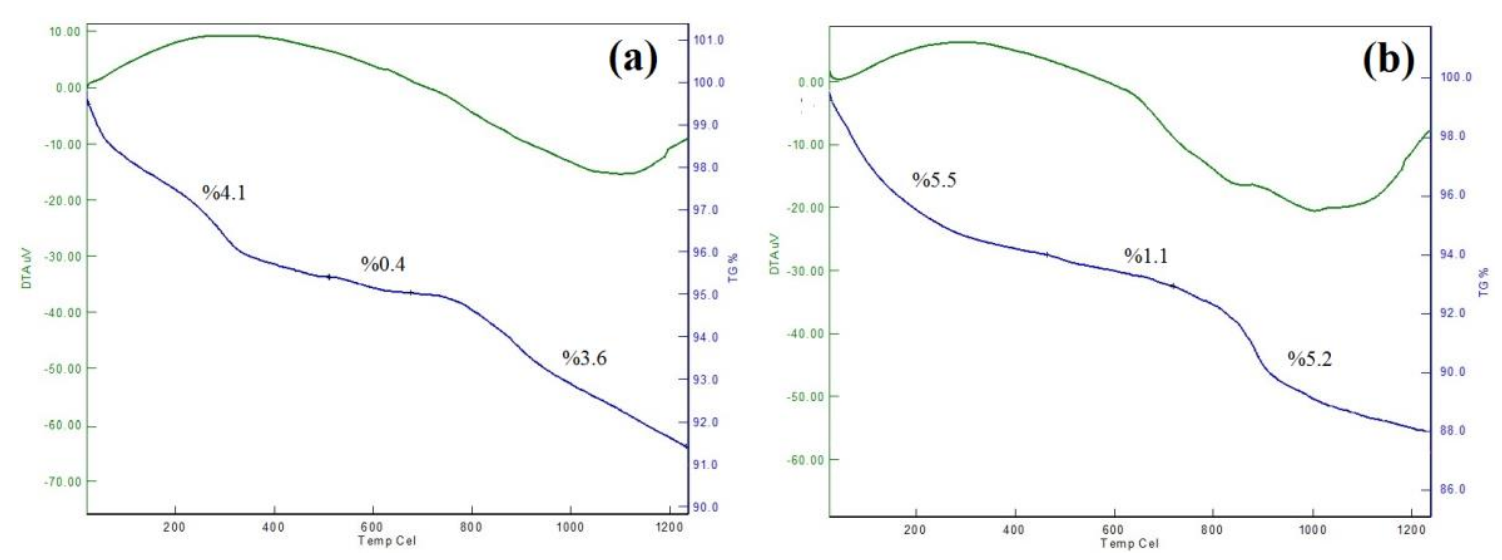

Şekil 7. (a) Saf ortamda ve (b) pentanoik asit varlığında üretilen hidroksiapatit kristallerinin TGA/DTA eğrileri.

Saf hidroksiapatit kristallerinin TGA ve DTA eğrileri incelendiğinde, termal bozunma işleminin temel olarak iki kademede gerçekleştiği görülmüştür. Birinci kademe 100-500 ${ }^{\circ} \mathrm{C}$ sıcaklık aralığında görülen ağırlık kaybı, nem ve kristal yapıda bulunan suyun uzaklaşmasından kaynaklanmaktadır. Bu kademe de toplam ağırlık kaybı \%4,1 civarındadır. 500-700 ${ }^{\circ} \mathrm{C}$ sicaklık aralığında ağırlık kaybı \%0,4 olup yok denecek kadar azdır. $700-1000{ }^{\circ} \mathrm{C}$ sicaklık aralığında meydana gelen ağırlık kaybı ise dihidroksilasyondan kaynaklanmaktadır. 30-1200 ${ }^{\circ} \mathrm{C}$ sıcaklık aralığında gözlenen toplam ağırlık kaybı \%8,1 olarak tespit edilmiştir [18].

1000 ppm pentanoik asit varlığında üretilen HAP kristallerin TGA/DTA sonuçları incelendiğinde saf ortama benzer bir davranış ile karşılaşılmıştır. Ancak katkı maddesi varlığında üretilen kristallerin bozunması sırasında toplam ağırlık kaybında meydana gelen değişim artmış ve \%11,8 olarak belirlenmiştir. Ağırlık kaybında meydana gelen bu artışın sebebi yapıya bağlanan katkı maddesinin de hidroksiapatit ile birlikte bozunmasından kaynaklanmaktadır. Ayrica bu bozunmalar DTA piklerinde de belirgin bir şekilde görülmektedir.

\subsection{Kinetik analiz}

$\mathrm{Bu}$ çalışmada, saf ve $1000 \mathrm{ppm}$ pentanoik asit varlığında üretilen hidroksiapatit kristallerinin termal bozunması sirasında gerekli olan ortalama aktivasyon enerjisi değeri $700-900{ }^{\circ} \mathrm{C}$ sıcaklık aralığında yani ana bozunma bölgesinde Kissinger modeli kullanılarak hesaplanmıştır. Bu yöntemde aktivasyon enerjisini hesaplamak için öncelikle 5, 10 ve $20^{\circ} \mathrm{C} /$ dak isıtma hızlarında TGA analizleri yapılmış ve maksimum pik sıcaklıkları belirlenmiştir. Sonuçlar Tablo 1'de verilmiştir.

Maksimum pik sıcaklıklarından faydalanarak hidroksiapatit kristallerinin aktivasyon enerjileri Şekil 8'de verilen doğruların eğimlerinden hesaplanmıştır. Saf ortamda üretilen hidroksiapatit kristalleri için aktivasyon enerjisi değeri 538,51 kJ/mol olarak belirlenmiştir. $\mathrm{Bu}$ değer bu konu ile ilgili yapılan çalışmalar ile ilgili sonuçlarla benzerlik göstermektedir [19]. Aktivasyon enerjisi değeri $1000 \mathrm{ppm}$ pentanoik asit varlığında ise $580,99 \mathrm{~kJ} / \mathrm{mol}$ olarak hesaplanmıştır. Katkı ortamında üretilen HAP kristallerin aktivasyon enerjisi saf ortama göre pentanoik asidin kristal yüzeyine tutunmasından dolayı artmıştır. 
Tablo 1. Farklı 1sıtma hızlarında saf ve katkı ortamında üretilen hidroksiapatitin maksimum pik sicaklıkları.

\begin{tabular}{ccc}
\hline Isitma hızı $\left({ }^{\circ} \mathrm{C} /\right.$ dak $)$ & Saf Ortam & Pentanoik Asit Ortamı \\
\hline 5 & $809^{\circ} \mathrm{C}$ & $813^{\circ} \mathrm{C}$ \\
10 & $823^{\circ} \mathrm{C}$ & $826^{\circ} \mathrm{C}$ \\
20 & $834^{\circ} \mathrm{C}$ & $836^{\circ} \mathrm{C}$ \\
\hline
\end{tabular}

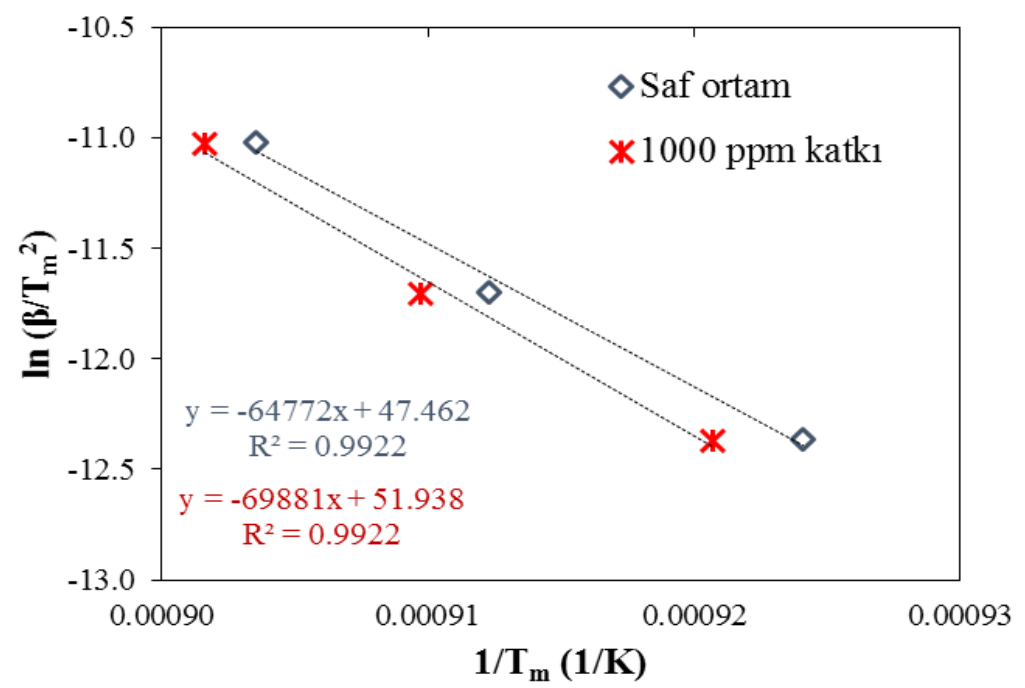

Şekil 8. Saf ortamda ve pentanoik asit varlığında üretilen kristallerinin Kissinger grafiği.

Aktivasyon enerjisinin yanı sıra, hidroksiapatit kristallerin termal bozunma mekanizmasının saf ve katkı maddesi varlığında belirlenebilmesi için Coats-Redfern metodundan faydalanılarak türetilen 10 farklı reaksiyon modeli kullanılmıştır [19-20]. Bu modellerin eşitlikleri Tablo 2'de verilmiştir. Optimum reaksiyon mekanizmasının belirlenebilmesi için Tablo 2'de verilen eşitlikler kullanılarak $\ln \left(\mathrm{g}(\mathrm{x}) / \mathrm{T}^{2}\right)$ değerlerine karşılık 1/T değerleri çizilmiş, elde edilen doğruların korelasyon katsayıları belirlenmiş ve sonuçlar Tablo 2'de verilmiştir.

Aktivasyon enerjisi değeri 1000 ppm pentanoik asit varlığında ise 580,99 kJ/mol olarak hesaplanmıştır. Katkı ortamında üretilen HAP kristallerin aktivasyon enerjisi saf ortama göre pentanoik asidin kristal yüzeyine tutunmasından dolayı artmıştır. Her bir model için $\mathrm{R}^{2}$ değerleri karşılaştırılmış ve en yüksek korelasyon katsayısına sahip model, termal bozunma sürecini en iyi karakterize eden model olarak seçilmiştir. Sonuçlardan da açıkça görüleceği üzere saf ve katkı ortamı içinde 3D difüzyon modelinin hidroksiapatitin termal bozunma sürecini en iyi karakterize model olduğu belirlenmiştir. 
Tablo 2. Coats-Redfern modeline göre faklı integral fonksiyonları ve belirlenen $\mathrm{R}^{2}$ değerleri.

\begin{tabular}{ccccc}
\hline No & Reaksiyon mekanizması & $\mathbf{g}(\mathbf{x})$ & $\begin{array}{c}\text { Saf ortam } \\
\left(\mathbf{R}^{2}\right)\end{array}$ & $\begin{array}{c}\text { Katkı ortam } \\
\left(\mathbf{R}^{2}\right)\end{array}$ \\
\hline 1 & 1D difüzyon & $\mathrm{x}^{2}$ & 0,988 & 0,984 \\
2 & 2D difüzyon & $\mathrm{x}+[(1-\mathrm{x}) \ln (1-\mathrm{x})]$ & 0,985 & 0,986 \\
3 & 3D difüzyon (Jander eşitliği) & {$\left[1-(1-\mathrm{x})^{1 / 3}\right]^{2}$} & $\mathbf{0 , 9 9 8}$ & $\mathbf{0 , 9 9 7}$ \\
4 & Anti-Jander eşitliği & {$\left[(1+\mathrm{x})^{1 / 3}-1\right]^{2}$} & 0,982 & 0,983 \\
5 & 3D difüzyon (Ginstling-Brounstein) & $1-(2 / 3) \mathrm{x}-(1-\mathrm{x})^{2 / 3}$ & 0,987 & 0,980 \\
6 & Power law & $\mathrm{x}$ & 0,952 & 0,962 \\
7 & Power law & $\mathrm{x}^{1 / 2}$ & 0,932 & 0,940 \\
8 & Power law & $\mathrm{x}^{1 / 3}$ & 0,935 & 0,953 \\
9 & Kimyasal kinetik (F1) & $-\ln (1-\mathrm{x})$ & 0,987 & 0,980 \\
10 & Kimyasal kinetik (F2) & {$\left[(1-\mathrm{x})^{(1-\mathrm{n})}-1\right] /(\mathrm{n}-1)$} & 0,988 & 0.983 \\
\hline
\end{tabular}

\section{Genel sonuçlar}

Bu çalışma kapsamında, pentanoik asidin hidroksiapatit kristalizasyonuna olan etkileri incelenmiş ve elde edilen genel sonuçlar aşağıda verilmiştir.

- XRD analiz sonuçları, saf ortamda üretilen kristallerin hidroksiapatit formunda olduğunu göstermiştir. Katkı maddesinin varlığı ise kristal yapısında herhangi bir değişikliğe neden olmamıştır.

- SEM analiz sonuçları, HAP kristallerinin saf ortamda çubuk formunda olduğunu göstermiştir. Kristalizasyon ortamına pentanoik asidin ilave edilmesiyle hem kristal morfolojisinde hem de kristallerin en/boy oranlarında değişim tespit edilmiştir.

- FTIR ve zeta potansiyeli analizleri, pentanoik asidin kristal yüzeyine adsorplandığını göstermiştir.

- BET analizi sonuçları, ortama katkı maddesinin eklenmesinin, hidroksiapatitin BET yüzey alanını azalmasına neden olduğunu göstermiştir.

- Termal analiz sonuçları, saf ve katkı varlığında elde edilen kristallerin benzer termal bozunma profiline sahip olduğunu göstermiştir. Ancak saf ortam ile karşılaştırıldığ bozunmaya bağlı meydana gelen ağırlık kayıpları pentanoik asit varlığında artmıştır.

- Kissinger modeli kullanılarak yapılan kinetik analiz sonucuna göre, hidroksiapatit kristallerin aktivasyon enerjisi ortama ilave edilen katkı maddesi nedeniyle yaklaşık olarak \%8 artmıştır.

- Coats-Redfern modelinden türetilmiş olan 10 farklı reaksiyon modeli dikkate alınarak yapılan hesaplamalar karşılaştırıldığında, 3D difüzyon modelinin hidroksiapatitin termal bozunma sürecini karakterize eden en iyi model olduğu tespit edilmiştir.

\section{Teșekkür}

$\mathrm{Bu}$ çalışma Marmara Üniversitesi Bilimsel Araştırma Projeleri Koordinasyon Birimi tarafından FEN-C-YLP-120417-0176 nolu proje kapsamında desteklenmiştir. 


\section{Kaynaklar}

[1] Koutsopoulos, S. ve Dalas, E., The effect of acidic amino acids on hydroxyapatite crystallization, Journal of Crystal Growth, 217, 4, 410-415, (2010).

[2] Kanchana, P. ve Sekar, C., Influence of sodium fluoride on the synthesis of hydroxyapatite by gel method, Journal of Crystal Growth, 312, 6, 808-816, (2010).

[3] Parekh, B., Joshi, M. ve Vaidya, A., Characterization and inhibitive study of gelgrown hydroxyapatite crystals at physiological temperature, Journal of Crystal Growth, 310, 7-9, 1749-1753, (2008).

[4] Chen, R. ve Shen, J., The synthesis of hydroxyapatite crystals with various morphologies via the solvothermal method using double surfactants, Materials Letters, 259, 126881, (2020).

[5] Wada, Y., Kudoh, K., Matsumoto, M. ve Onoe, K., Synthesis and characterization of strontium fluor-hydroxyapatite nanoparticles for dental applications, Microchemical Journal, 153, 104485, (2020).

[6] Wada, Y., Kudoh, K., Matsumoto, M. ve Onoe, K., Development of hydroxyapatite crystallization utilizing the contact reaction of a minute droplet with atmospheric plasmas, Journal of Crystal Growth, 466, 1-5, (2017).

[7] Dalmônico, G.M.L., López, E.O., Longuinho, M.M., Checca, N.R., Farina, M., Ersen, O., Rossi, A.M. ve Rossi, A.L., Materials Chemistry and Physics, 237, 121862, (2019).

[8] Zhang, Y., Lu, J., Wang, J., Yang, S. ve Chen, Y., Synthesis of nanorod and needle-like hydroxyapatite crystal and role of $\mathrm{pH}$ adjustment, Journal of Crystal Growth, 311, 23-24, 4740-4746, (2009).

[9] Aneem, T.H., Saha, S.K., Jahan, R.A., Wong, S.Y., Li, X. ve Arafat, M.T., Effects of organic modifiers and temperature on the synthesis of biomimetic carbonated hydroxyapatite, Ceramics International, (2019).

[10] Liuyun, J., Chengdong, X., Lixin, J. ve Lijuan X., Effect of hydroxyapatite with different morphology on the crystallization behavior, mechanical property and in vitro degradation of hydroxyapatite/poly(lactic-co-glycolic) composite, Composites Science and Technology, 93, 61-67, (2014).

[11] Nasiri-Tabrizi, B., Pingguan-Murphy, B., Basirun, W.J. ve Baradaran, S., Crystallization behavior of tantalum and chlorine co-substituted hydroxyapatite nanopowders, Journal of Industrial and Engineering Chemistry, 33, 316-325, (2016).

[12] Edwin, N. ve Wilson, P., Investigations on sonofragmentation of hydroxyapatite crystals as a function of strontium incorporation, Ultrasonics Sonochemistry, 50, 188-199, (2019).

[13] Gonzalez-McQuire, R., Chane-Ching, J.Y., Vignaud, E., Lebuglec, A. ve Manna, S., Synthesis and characterization of amino acid-functionalized hydroxyapatite nanorods, Journals of Materials Chemistry, 14, 2277-2281, (2004).

[14] Kissinger, H.E., Reaction kinetics in differential thermal analysis, Analytical Chemistry, 29, 11, 1702-1706, (1957).

[15] Chen, L., Mccrate, J.M., Lee, J.C.M. ve Li, H., The role of surface charge on the uptake and biocompatibility of hydroxyapatite nanoparticles with osteoblast cells, Nanotechnology, 22, 10, 693-698, (2011). 
[16] Koutsopoulos, S., Synthesis and characterization of hydroxyapatite crystals: A review study on the analytical methods, Journal of Biomedical Materials Research, 62, 4, 600-612, (2002).

[17] Latocha, J., Wojasiński, M., Sobieszuk, P., Gierlotka, S. ve Ciach, T., Impact of morphology-influencing factors in lecithin-based hydroxyapatite precipitation, Ceramics International, 45, 17, 21220-21227, (2019).

[18] Wang, T., Dorner-Reisel, A. ve Müller, E., Thermogravimetric and thermokinetic investigation of the dehydroxylation of a hydroxyapatite powder, Journal of the European Ceramic Society, 24, 4, 693-698, (2004).

[19] Khawam, A., ve Flanagan, D.R., Role of isoconversional methods in varying activation energies of solid-state kinetics I. isothermal kinetic studies, Thermochimica Acta, 429, 93-102, (2005).

[20] Ebrahimi-Kahrizsangi, R. ve Abbasi, M.H., Evaluation of reliability of CoatsRedfern method for kinetic analysis of non-isothermal TGA, Transactions of Nonferrous Metals Society of China, 18, 217-221, (2008). 